\title{
Chapter 18 \\ Sleepy Doctors: Work Hours \\ and the Accreditation Council \\ for Graduate Medical Education
}

On March 5, 1984, Bennington College freshman Libby Zion died at New York Hospital. She had been admitted the night before with vague symptoms and strange jerking motions. After consulting with her family physician, the residents on call gave her intravenous solutions for possible dehydration and prescribed meperidine to control her jerking motions. They then left to take care of other patients. Luise Weinstein, the first-year resident, was responsible for 40 other patients. No sleep for her.

Libby Zion did not improve; she became more agitated. Weinstein ordered restraints, which Zion fought against. Finally, she went to sleep. But her temperature rose, and by 6:30 AM it reached $107^{\circ} \mathrm{F}$. Weinstein took measures to cool her down, but she quickly deteriorated, had a cardiac arrest, and could not be resuscitated.

Her father, Sidney Zion, a lawyer and a writer for the New York Times, was furious. He was convinced her death was due to inadequate care by poorly supervised, overworked residents. In a New York Times op-ed piece, he wrote: "You don't need kindergarten to know that a resident working a 36-hour shift is in no condition to make any kind of judgment call—forget about life-and-death." He decried the lack of supervision of the residents and accused the doctors of murder. He launched an unremitting public campaign for justice [1].

A full investigation later concluded that the probable cause of death was a reaction between the prescribed meperidine and an antidepressant she was taking, phenelzine. This interaction was not well-known, 
and, in fact, at a hearing 2 years later several chairmen of departments of medicine at prominent medical schools stated they had never heard of the interaction prior to this case.

Sidney Zion pursued the legal challenge, however, and in 1986 a grand jury charged the residents with negligence. However, after multiple reviews and conflicting findings by state regulatory bodies over several years, an appeals court in 1991 cleared them of all charges [2]. Zion then filed a civil suit which in 1995 concluded with a judgment that the primary care physician and the residents pay Zion $\$ 375,000$ [2].

\section{Residency Training}

The system for training doctors goes back to the 1890s, when William Stewart Halsted, the professor of surgery at the Johns Hopkins Hospital, formalized the training of surgeons. Halsted believed that total immersion in the care of patients was the best way to learn about disease and treatment and to develop a sense of commitment to the patient.

After completing medical school, surgical trainees at Hopkins were required to literally live at the hospital - the origin of the term "resident"- and were discouraged from marrying. Supervised by senior physicians called "Attending Physicians," they were responsible for all aspects of care, including menial tasks such as drawing blood for tests, changing dressings, and transporting patients for tests. It was a long process: up to 10 years for some.

Other specialties adopted the residency concept, gradually modifying it to require 30 hours in-hospital on alternate days, the custom at the time of the Libby Zion case. Surgical training typically required 5 years, medical specialties, three. Residents (also called "house officers") were not paid for their services-after all, they were getting a free education - but they got free uniforms and room and board while in the hospital.

Although they were budding professionals, hospitals often treated them like military academy plebes. An apocryphal story that I heard while a surgical resident at the Massachusetts General Hospital many years later was that a former hospital director was so incensed with residents standing around with their hands in their pockets that he had the pockets of their uniforms sewn shut! 
The number of residencies increased as the number of specialties expanded dramatically in the mid-twentieth century. In addition to supervised clinical experience and bedside teaching, programs provided teaching conferences. Few residents were paid anything until the 1960 s, when they began to receive a meager "stipend" to meet personal expenses-nothing for living expenses outside the hospital, such as food and rent. Hospitals found it convenient to ignore the reality that now most residents were married, and some had children.

Forty years later, in 2001, the mean salary for residents was $\$ 40,000$ a year, an average of $\$ 9.61$ an hour for the typical 80-hour week [3]. Residents' expertise, skills, and dedication enable faculty at teaching hospitals to take care of very sick and complicated patients without hiring help or needing to be present all the time. The "purpose" of residency training may be education, but its practical effect-and attraction for the hospital and its doctors-is the 24/7 service doctors in training provide at below minimum wages.

The sleep deprivation and high workloads of busy acute clinical care practice pose a threat to patient safety for any physician, but especially for residents during training. It has been demonstrated, and we all know from personal experience, that judgment and performance suffer when we are up all night or are excessively fatigued from overwork. There is no reason to believe that physicians have some special immunity to these effects. Other critical industries such as commercial aviation and nuclear power recognize the effects of sleep deprivation and strictly limit work hours. Why should medicine be different? The Zion case forced the public and the profession to confront these issues.

\section{Early History—What Happened After Zion}

Following the grand jury indictment in 1986, Health Commissioner David Axelrod (the same person who later funded the Harvard Medical Practice Study) established a blue-ribbon committee headed by Bertrand Bell, the "Bell Commission," to investigate the training and supervision of doctors. It recommended limiting resident work hours and improving supervision [4].

In 1989 New York State adopted the Commission's recommendations and legislated that residents could not work more than 80 hours 
a week or more than 24 consecutive hours. It also required that they have round-the-clock supervision by attending physicians. Two hundred million dollars was appropriated to hire additional ancillary help and board-certified physicians to assist New York hospitals in compliance $[5,6]$.

It is worth noting that although it is broadly accepted, the 80-hour limit was not at the time evidence-based. Later studies showed, however, that working more than 80 hours was linked to increased depression, suicide, and needlestick injuries of residents.

On the national level, the professional organization responsible for oversight of most residency and fellowship training programs, the Accreditation Council for Graduate Medical Education (ACGME), took notice. The ACGME is a private, not-for-profit organization that sets standards for US graduate medical training (residency and fellowship) programs and accredits training programs based on compliance with these standards. A resident must successfully complete training in an accredited institution to be eligible for certification in their specialty and licensure to practice.

Within ACGME, resident duty hour standards are set across all specialties by the Board of Directors in concert with the chairs of the 30 specialty review committees in the common program requirements. Additional specific and more detailed standards are proposed by the individual Residency Review Committees for each specialty. In addition, there are many subspecialties (such as gastroenterology, nephrology, and cardiology in Internal Medicine) that propose their own standards. In 2018, there were approximately 830 ACGME-accredited institutions sponsoring approximately 11,200 residency and fellowship programs in 180 specialties and subspecialties [7].

In 1988, ACGME spoke up with whispered voice to suggest limiting call to every third night and to permit—not require-its individual specialty Residency Review Committees to incorporate requirements related to work hours in their standards. It did not mandate, as part of the shared requirements, that all specialties adopt a common standard. Not surprisingly, its general request had limited effect. Over the next 2 years, only six specialties_-none of them surgical-instituted a limit of 80 hours per week.

New York State did little better. With over 100 teaching hospitals, its hospitals train $15 \%$ of the resident physicians in the USA, but it did 
not initially vigorously enforce its 1989 regulations. This led New York City Public Advocate, Mark Green, in 1994 and 1997 to investigate compliance and report widespread violations. A Department of Health survey in 1998 of 12 hospitals in New York City found that $37 \%$ of residents worked more than allowed and $77 \%$ of surgical residents worked more than 95 hours per week [8]. The state fined four hospitals $\$ 20,000$ each and increased the maximum fine to $\$ 50,000$. Two years later, the state funded and issued a contract for monitoring hospitals and fining them for noncompliance [9].

The pressure for reform continued to build. In April 2001, the NYC residents' union, the Committee of Interns and Residents of the SEIU (CIR), the Public Citizen Health Research Group, the American Medical Student Association, and Dr. Bertrand Bell, petitioned the Occupational Safety and Health Administration to establish and enforce a federal work hour standard for residents [10]. It didn't happen.

In November 2001, a bill was introduced in the House of Representatives to limit work hours of residents to 80 hours a week and to provide for federal enforcement [11]. Meanwhile, the Association of American Medical Colleges (AAMC) issued a policy statement recommending limits on work hours. The ACGME became more active in enforcement; in 2002 it withdrew accreditation of the general surgery program at Yale-New Haven Medical Center because of excessive work hours [12]. Finally, seeking to forestall the pending federal regulation, the ACGME decided it was time to act.

\section{ACGME Regulations}

In 2002 the ACGME announced new regulations of resident hours and workloads, to take effect July 1, 2003 [13]. Although most people had seen it coming, it still aroused great consternation. The ACGME had already gradually stiffened requirements, limiting overnight oncall duty to every third night and requiring residents to have 1 day off every 7 days worked. A number of non-surgical specialties had imposed an 80-hour work week limit.

The surgeons, however, had rejected the hour limits. The Residency Review Committee for Surgery gave hospital surgical program directors responsibility for "appropriate" duty hours. They stressed that 
continuity of care must take precedence without regard to time of day, call schedules, or number of hours already worked. Work weeks of 100-120 hours were still common [14, 15].

The new regulations made the 80-hour week mandatory for all specialties and added a 24-hour limit for on-call duty. Hospitals were required to monitor work hours and reduce residents' responsibility for patient care support services of no educational value, such as drawing blood for tests, starting intravenous lines, and transporting patients [16]. The ACGME would monitor compliance.

These stronger standards, however, fell short of the AMA and AAMC recommendations for shorter on-call hours, or those in the legislation proposed by Congress. Nonetheless, both the AMA and the AAMC endorsed the changes. The new rules were met with skepticism from CIR, Public Citizen, and the New York Times [17]. They also aroused strong feels within the profession-pro and con-the latter especially among the surgeons.

\section{The Duty Hours Debate}

The arguments for hour and workload limitations are basically two: that it will reduce injuries and that it will improve residents' mental health and well-being. The evidence of the potential harm to patients from sleep deprivation is abundant. Many studies over the years of its effects on various populations have shown the risk of sleep deprivation $[18,19]$, including a memorable study that demonstrated that impairment of performance after 24 hours of sustained wakefulness is equivalent to having a blood alcohol concentration of $0.10 \%$ [20].

Specific studies of medical residents' performance also confirm its ill effects [21]. One controlled study of first year residents showed that those with 24-hour sleep deprivation made 36\% more serious errors than those who worked 16 hour days, and they made over 5 times as many serious diagnostic errors [22]. Other studies showed residents made twice as many mistakes detecting cardiac arrhythmias when sleep deprived and twice as many technical errors in simulated laparoscopic surgery [23].

A survey of residents showed that $41 \%$ reported fatigue as a cause of serious mistakes; of those, $31 \%$ were fatal [22]. A meta-analysis of 
studies by the ACGME found that after 24-30 hours of sleep deprivation, clinical performance of residents dropped from the 50th to the 7th percentile of performance when rested [24].

Sleep deprivation is also hazardous to the residents themselves. During night call, they are twice as likely to suffer a needlestick injury [25]. Driving home after an "all-nighter," the chance they will sustain a motor vehicle crash that injures the resident or others is increased by $168 \%$ [26], and the risk that the accident will be fatal is also increased.

The second argument in favor of shorter hours is that resident wellbeing is enhanced. Learning is improved by the fact that residents are sufficiently awake and alert to benefit both from clinical experience and from formal educational activities. It was a common experience for residents to fall asleep during conferences or sometimes even while standing on rounds. (Your author remembers having this experience.)

Mood is also improved. Fatigue increases depression, anxiety, confusion, and anger that lead to detachment and lack of compassion for patients [21]. With adequate rest, attitudes and overall mental health improve. Finally, more humane hours permit the resident to maintain a balance between personal and professional lives, which would give them a better attitude toward their work and their patients.

The arguments against the proposed limits came largely from the general surgeons and surgical specialists, who raised issues of learning and responsibility. They were concerned that disruption of continuity of care by shorter work hours and more frequent shifts would deprive the trainee of the opportunity to see a clinical episode evolve and participate in all aspects of care [27]. Residents would miss important learning opportunities. They would not participate in enough operations to develop the needed skills and judgment.

They held out the specter of a surgical resident being forced to drop out of an operation because his time was up. They decried "shift medicine." They worried that young surgeons wouldn't develop a sense of responsibility for their patients. Following the patient through the night and when fatigued was, they maintained, essential to the inculcation of accountability and professionalism [27]. Others agreed: these are critical issues; their fears were justified.

Surgical residents also agreed. They live for the operating room. As we used to joke when I was a surgical resident, "The only problem 
with being on every other night is that you miss half of the good cases." It is difficult for the public or non-surgical physicians to fully appreciate the nature of surgical residency or its allure for residents. Participating in a surgical operation is an exhilarating experience. You see inside the human body, handle its organs, and restore its integrity by removing disease or repairing an injury. There is nothing like it in the world.

Surgical residents want to be able to do it themselves, and they can see they need to practice-a lot. They become almost obsessive about "doing more cases." Like all doctors, they want to do a good job, to become competent. They are willing to pay the price in high workloads and long hours, although they worry about its effect on their ability to give good care. A surgical resident once shared her feelings with me, "The thing wrong with having too many patients is that it keeps me from giving them the best care possible."

Years later, surgeons still have strong feelings about their residency years. They look back with nostalgia at the long hours, midnight operations, and heroic efforts to save the life of a badly injured trauma victim. They learned by doing, and it was exciting. In retrospect, some may resent the time it took away from their families, but they have no question it was worth it. These experiences reinforce their mindset about training. As we see daily on the political scene, once established, mindsets are hard to change. Evidence, facts, and even compelling contradictory data don't do it.

Other concerns were that the residents would not have time for reading and reflecting on what they were learning from their clinical experience and that shorter shifts would require more frequent handoffs of care to another doctor, which would cause more errors [27]. These were all important issues that needed to be addressed.

Interestingly, in the debate that followed, no one brought up the fact that most countries in the European Union follow its recommendations of a maximum of 48 hours per week and 13 hours maximum shifts. Are European surgeons poorly trained? Do they have poorer outcomes? There is no evidence they do.

But implementing the new rules would require substantial adjustments by hospitals. The purpose of residency training may be education, but residents also provide many services for the hospital that are of no educational value that can be performed by those with far less 
training. Eliminating these non-educational services was now essential—and long overdue. Filling the gap by hiring more residents was not an option since CMS would not likely fund it. The choices were to increase the workloads of the attendings or to hire more doctors and physician's assistants. A 1994 study estimated that the national cost of these changes would be $\$ 1.4-1.8$ billion [28].

Some, however, saw that redesigning the system of care to shift resident responsibilities to others would provide an opportunity to better align clinical responsibilities with other educational needs and to rethink the nature of the workplace. The burgeoning patient safety movement was making clear that health-care organizations badly needed to reform their work practices and change their attitudes toward work. It was time to recognize exhaustion not as a sign of dedication but as a risk to patient safety [21].

Regarding responsibility and dedication, Jeff Drazen, editor of the NEJM pointed out, "The role models that trainees see and the integrity of the environment in which they work appear to be far more important for instilling the professional ethos than the duration of the on-call schedules." [27]

\section{What Happened: 2003-2008}

Sadly, few surgical training programs and hospitals saw it that way. Most did not see the requirements as an opportunity to improve graduate medical education, but as a threat to the status quo. They refused to change. However, the ACGME required programs to report compliance based on regular reports by the residents of the hours they worked.

The residents were in a bind two ways. If they reported longer hours than permitted, they would incur the ire of their supervisors, jeopardizing both their clinical experience and recommendations for positions after training. And if the program was found in violation, it could lose its accreditation, making the resident ineligible to become boardcertified. Program directors made it clear that they expected the reports to show compliance. So residents falsified their reports.

The extent of this deception came to light in 2006, when the Harvard Work Hours Study Group published the results of a confidential study of reporting by first year residents in 700 programs. It showed gross 
discrepancies: $83.6 \%$ reported work hours that were in violation of the ACGME standards. Working shifts greater than 30 consecutive hours was reported by $67.4 \%$, working more than 80 hours a week was reported by $43 \%$, and $43.7 \%$ reported not having 1 day in 7 off duty [29].

The ACGME, however, relying on the "official" reports from the program directors reported near-universal compliance with the ACGME standards during the same reporting period, maintaining that only $5.0 \%$ of programs were not compliant and that only $3.3 \%$ of residents reported violations of the 80-hour rule [29].

Apparently, the leaders of some Residency Review Committees were concerned about responsibility, continuity, and dedication, but it was okay for program directors to force residents to lie. The new rules weren't being observed, and everyone knew it.

\section{The IOM Panel}

Other forces were at work. As noted, a series of research studies had emerged that documented the effects of sleep deprivation on errors and harm to patients [26] and harm to residents [25, 26]. Other studies showed that shorter work hours reduced serious medical errors [22, 30, 31] and improved residents' health and education [32]. The CIR continued to press for enforcement. Congress again took notice. In 2007, the House Committee on Energy and Commerce, responding to the evidence linking medical errors to sleep deprivation and overwork and noncompliance with hour limits, requested the IOM to conduct a study and make recommendations.

The IOM convened a distinguished panel of patient safety and quality experts, policy makers, consumer representatives, physicians, nurses, and program directors, who deliberated and had hearings over an 18-month period. In December 2008 it issued its report, Resident duty hours: Enhancing sleep, supervision and safety [33]. The IOM called for new measures that would (1) focus not just on the number of hours worked, but on alleviating fatigue and loss of sleep, (2) increase supervision by senior physicians, (3) improve processes for transferring responsibilities from physicians going off duty to those coming on, and (4) stiffen enforcement by initiating federal oversight of the ACGME regulations [33]. 
It also called on programs not to reduce hours without putting sufficient funding and resources in place to allow for the reduction of hours without overburdening those residents left behind in the hospital. It estimated the total additional cost at $\$ 1.7$ billion per year.

The IOM Committee took special aim at violations of current duty hour rules, noting that non-adherence to duty hours "is substantial and underreported, and that more intensified monitoring is necessary immediately." It noted "residents fail to accurately report their duty hours for multiple reasons, including fear of repercussions from their supervisors or, at the extreme, fear of causing a training program to lose its accreditation."

It called on the ACGME to address this issue by making unannounced audits of duty hour compliance and implementing protection for whistleblowers. It called on CMS to conduct periodic reviews of ACGME's duty hour monitoring and on the Joint Commission to include adherence data in its surveys and accreditation process.

The IOM's specific recommendations were built on the existing regulations and were consistent with the lessons learned from sleep research and recent studies of residents' work. It called for a maximum of 80 hours duty a week, no more than 16 hours without sleep, maximum on-call duty one night in 3 , one full day off each week and 48 hours off once a month, 12 hours off after a night shift, and 48 hours off after 3 or 4 consecutive nights.

The IOM had spoken. The report was hailed not just for the duty hours standards but also for its emphasis on supervision of residents and external oversight of the ACGME. In addition to the IOM panel recommendations, there was mounting public pressure to do something. People were concerned about being harmed by a sleep-deprived doctor. How would the ACGME respond?

\section{ACGME Duty Hour Task Force}

We would soon see. When the ACGME implemented its first set of regulations in 2003, it promised a 5-year review. That time had come, and, with the IOM report and the continuing threat of Federal regulation, the ACGME needed to act. In 2008, it commissioned a 16-member Duty Hours Task Force composed of its members, trustees, 
medical educators, and a consumer, to review relevant research, hear testimony, and draft new standards.

There was concern that limited hours had created a "shift mentality" that conflicted with the physician's moral and professional responsibility to the patient, that programs' focus on duty hours diverted their attention from making needed changes in the learning environment, and that residents were conflicted about leaving patients to comply with the rules [34].

The Task Force discussed the need for enhanced supervision and faculty oversight, improving handovers, and the need to increase attention to patient safety. Research showed that the 2003 regulations had not led to increased hours of sleep. It also showed that reduced hours had no effect on mortality.

Regarding hours, would they heed the IOM recommendations? The leadership was ready to move. The Council of Review Committee Chairs was not so sure. The early signs were not encouraging. At the ACGME June 2009 Congress devoted to duty hours, many representatives of specialty societies spoke out against implementing the IOM recommendations.

\section{Harvard Conference on Duty Hours}

Meanwhile, many safety leaders thought the IOM recommendations deserved a broader review, with input not just from leaders of graduate medical education but also from those most affected: patients and residents, nurses, hospitals, and training directors, as well as policy makers and others. The changes proposed by the IOM would affect hundreds of thousands of physicians and residents, over 1000 hospitals, and have a global budget in the billions [35]. Implementing them would be a huge challenge.

The organized voice of residents, the CIR/SEIU, representing 13,000 residents in New York, was particularly concerned about what the ACGME would do. To put pressure on hospitals to implement the IOM recommendations regardless of what the ACGME required, they thought a persuasive strategy would be to provide advice from experts and evidence from those who had successfully implemented hours and workload changes. 
At CIR's behest and funding, the leaders of sleep science and resident hours research, Chuck Czeisler and Chris Landrigan, and I convened a 2-day work hours conference at Harvard Medical School in June 2010, "Enhancing sleep, supervision and safety: What will it take to implement the Institute of Medicine recommendations?"

Attendees included quality improvement experts, medical educators, hospital administrators, consumers, regulators, sleep scientists, patient advocates, policy makers, a resident, a medical student, and two members of the IOM committee that produced the report. We also had representatives from AHRQ, JCAHO, CMS, and AHA, as well as training directors who had successfully implemented changes in their training programs to meet the 2003 requirements.

A recent survey had shown the disconnect between public perception and reality. The vast majority of the public had no idea that doctors worked 24 hours or more without sleep. When informed of this, only $1 \%$ supported it. Eighty percent supported a limit of 16 hours. Importantly, $81 \%$ believed that the patient should be informed if the doctor treating them had been working for more than 24 hours: $80 \%$ would want a different doctor. Ninety one percent favored strict rules to assure direct on-site supervision by attendings [36].

Roundtable discussions were held on eight topics: workload and supervision, work hours, moonlighting, physician safety, handovers and quality improvement, monitoring and oversight of the ACGME, financial support for implementation, and future research. The head of ACGME, Tom Nasca, himself a supporter of more humane working conditions, addressed the group.

The most memorable feature of the conference was the presentation of three case studies by training directors of programs in internal medicine, obstetrics, and surgery who had successfully developed new programs that functioned well within the hour limits. They showed that the objectives of training could be met and that residents attended more conferences and had higher morale. Both residents and faculty at these institutions were pleased with the results.

In its report, Implementing the 2009 Institute of Medicine Recommendations on Resident Physician Work Hours, Supervision, and Safety, the conference made 27 recommendations of necessary and practical steps that are needed to make the new limits work [35]. It concluded that innovators had demonstrated that hours and 
workloads can be reduced without compromising clinical experience or inhibiting the learning of responsibility, but regulation and financial incentives were needed to facilitate spread.

\section{The ACGME Response}

Just a week after the conference, on June 23, 2010, the ACGME Duty Hours Task Force issued its recommendations. It rejected most of the IOM duty hour recommendations except for a maximum duty period of 16 hours for first-year residents (only) and on-site supervision of first-year residents by faculty [34].

The 80-hour work week was retained, as well as limiting on-call duty to every third day (except for "night floats," who were limited to six consecutive nights), and 24 hours off duty every 7 days. However, there was a loophole: programs could apply to be more "flexible" in integrating service with teaching, which could include increasing work hours to 88 hours a week.

The recommendations of the Task Force were accepted by the Council of Review Committee Chairs, and in September 2010 the ACGME Board of Directors approved new rules that would go into effect July 1, 2011.

The patient safety community was disappointed. The reaction focused on duty hours. Most didn't believe the ACGME was making a commitment to ensure adequate supervision and a better learning environment.

In fact, the major thrust of the ACGME report was not about duty hours; it was about the learning environment. The Task Force was explicit: "The goal of the ACGME's new approach to duty hours is to foster a humanistic environment for graduate medical education that supports learning and the provision of excellent and safe patient care. The graduate medical education community has a moral responsibility to prepare residents to practice medicine outside the learning environment, where they will be unsupervised, must think independently, and must function when fatigued" [34].

"Paramount is an environment characterized by supervision customized to residents' level of competence, faculty modeling of fitness 
for duty, and the provision of high-quality care in a team setting and an institutional culture of safety." The new standards reflected this commitment.

The seriousness of the commitment of the ACGME to changing the learning environment was made clear by the significant expansion of its role. It would establish a new program of annual site visits of sponsoring institutions that would be separate from accreditation and would not focus just on duty hour compliance but also on supervision and the provision of a safe and effective environment for care and learning.

This was a big change, and it should have a major impact on residency training and patient safety. It is what Sidney Zion called for 25 years earlier.

The recommendation of the Duty Hours Task Force for evaluating the learning environment did not arise de novo. Ten years earlier there had been discussions at ACGME about how to improve the design of residency and fellowship programs through the use of a developmental framework and move the accreditation system to a focus on outcomes using a continuous quality improvement philosophy [37].

In 2009, ACGME CEO Tom Nasca convened a group of healthcare quality and patient safety experts, chaired by Carolyn Clancy, director of AHRQ, and Timothy Flynn, the chair of the ACGME Board of Directors, to make recommendations on how residency programs could be motivated to do a better job in training residents in patient safety.

One of the problems was that Graduate Medical Education programs were often managed at the department level, while quality and safety efforts were carried out at the hospital level from which the residents were not commonly included. How could they be integrated?

The group recommended that ACGME conduct an additional type of on-site visit, separate from and unrelated to accreditation visits. These visits would evaluate the learning environment, the residents' progress in achieving competencies, how they were integrated into the quality and safety activities of the hospital, and how programs were dealing with concerns about disparities and transitions in care. 


\section{CLER}

To implement this ambitious program, Nasca brought Kevin Weiss, a member of the quality and safety workgroup and an immediate past $\mathrm{CEO}$ and president of the American Board of Medical Specialties into ACGME to develop the program. ACGME labeled it Clinical Learning Environment Review (CLER).
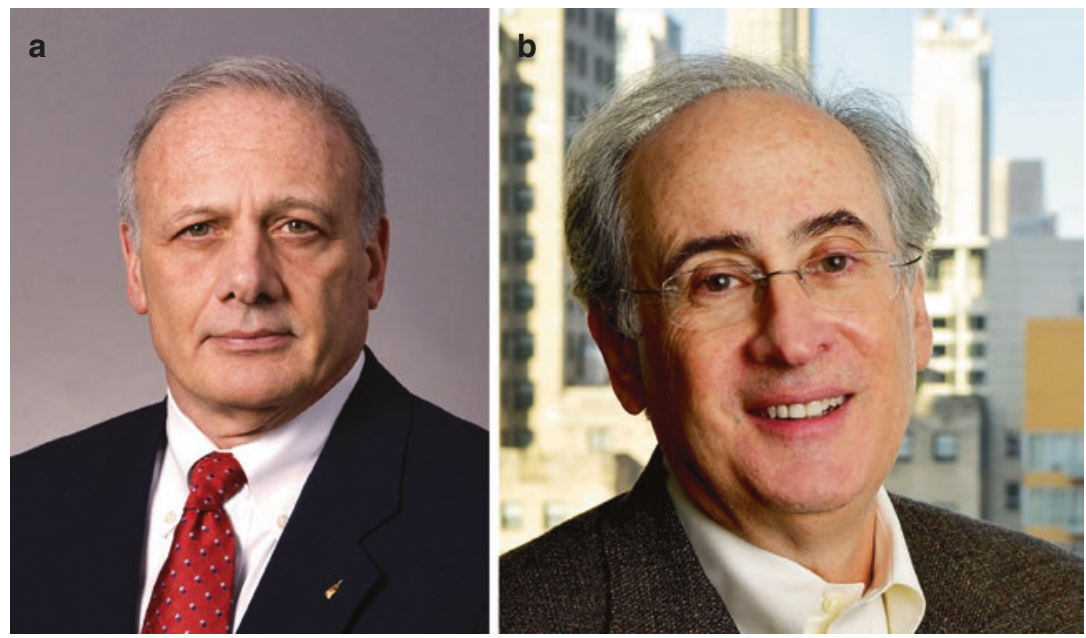

(a) Tom Nasca and (b) Kevin Weiss

The core of the CLER Program is a commitment to formative assessment and feedback regarding a residency training program's engagement in six focus areas: patient safety; health-care quality; care transitions; supervision; fatigue management, mitigation, and duty hours; and professionalism. The CLER Program required biannual formative assessment by each accredited sponsor of graduate medical education. It was designed to provide direct feedback to teaching hospitals and health-care organizations and to inform the ACGME accreditation process on issues in the six focus areas [38].

Training programs were now labeled Clinical Learning Environments (CLEs). Through periodic site visits that involve the program directors, residents, and the CEOs, the program aims to 
stimulate conversations and motivate CLEs to build upon their strengths and internally address opportunities for improvement.

Visits focus on six areas of concern: (1) the engagement and demonstration of meaningful participation of residents in the patient safety programs of the institution; (2) the engagement and demonstration of meaningful participation of residents in the institutional quality of care activities and participation in programs related to reduction of disparities in clinical care conducted by the institution; (3) the establishment and oversight of institutional supervision policies; (4) the effectiveness of institutional oversight of transitions of care; (5) the effectiveness of duty hours and fatigue mitigation policies; and (6) activities addressing the professionalism of the educational environment [39].

\section{Milestones}

In addition to the CLER program, ACGME established the milestone program. ACGME standards require residency and fellowship program directors to periodically assess each individual resident and fellow. These assessments use a variety of tools, including direct observations; global evaluation; audits and review of clinical performance data; multisource feedback from peers, nurses, patients, and family, simulation; self-assessment; and in-service training examinations [40].

ACGME requires semi-annual assessment of each resident and fellow on their progress in achieving milestones in the six domains of clinical competency that had been described as relevant for all medical practice by the ACGME and the ABMS in 1999. (See Chap. 20 for a discussion of the six competencies.)

Residency programs had for some time been required to configure curricula and evaluation processes in the framework of the six competencies under the Outcome Project, launched in 2001. Achieving the competencies was, in fact, the purpose of the programs. Under the ACGME, the training programs would ensure achievement of the six competencies. Certification programs, under the ABMS, would ensure that physicians maintained them. 
Implementing outcome-based, i.e., competency-based, education into residency training was a big challenge for programs. Program directors and faculty had struggled since the launch of the Outcome Project to understand what competencies meant and what they looked like in practice [39]. They had different ideas of how to do it and different sets of skills for making the changes. There was wide variation between specialties and between programs within a specialty.

The concept of developmental milestones grew out of this need to move the outcomes project forward and deal with these variations. Milestones use narratives to describe the educational and professional trajectories of residents from the beginning of their education through the achievement of competency and the ability to enter into the unsupervised practice of medicine [40]. They define the stages in achieving competency for each of the six domains (Boxes 18.1 and 18.2).

\section{Box 18.1 Milestone template}

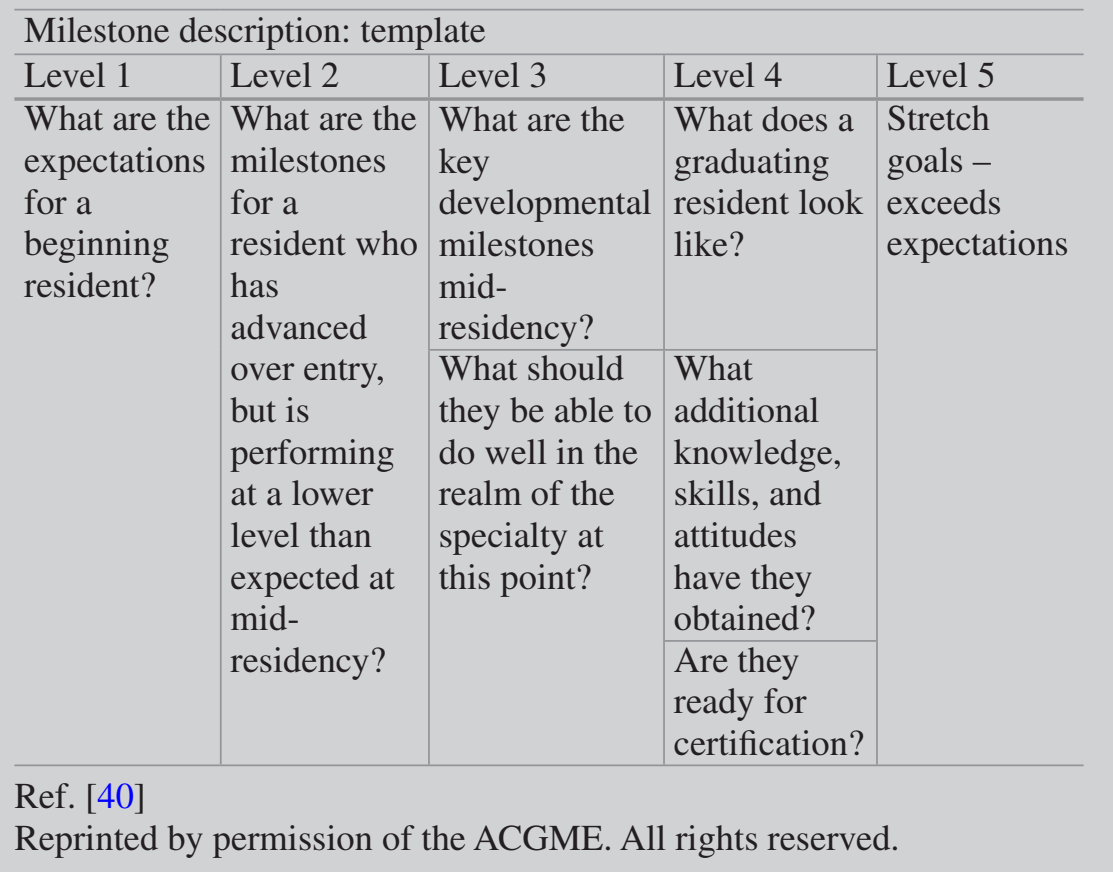




\section{Box 18.2 Milestones for systems-based practice 1: patient safety and quality improvement}

\begin{tabular}{|c|c|c|c|c|}
\hline Level 1 & Level 2 & Level 3 & Level 4 & Level 5 \\
\hline $\begin{array}{l}\text { Demon- } \\
\text { strates } \\
\text { knowledge } \\
\text { of common } \\
\text { patient } \\
\text { safety } \\
\text { events }\end{array}$ & $\begin{array}{l}\text { Identifies } \\
\text { system } \\
\text { factors that } \\
\text { lead to } \\
\text { patient } \\
\text { safety events }\end{array}$ & $\begin{array}{l}\text { Participates } \\
\text { in analysis of } \\
\text { patient safety } \\
\text { events } \\
\text { (simulated or } \\
\text { actual) }\end{array}$ & $\begin{array}{l}\text { (simulated } \\
\text { or actual) }\end{array}$ & $\begin{array}{l}\text { Actively } \\
\text { engages } \\
\text { teams and } \\
\text { processes to } \\
\text { modify } \\
\text { systems to } \\
\text { prevent } \\
\text { patient safety } \\
\text { events }\end{array}$ \\
\hline $\begin{array}{l}\text { Demon- } \\
\text { strates } \\
\text { knowledge } \\
\text { of how to } \\
\text { report } \\
\text { patient } \\
\text { safety } \\
\text { events }\end{array}$ & $\begin{array}{l}\text { Reports } \\
\text { patient } \\
\text { safety events } \\
\text { through } \\
\text { institutional } \\
\text { reporting } \\
\text { systems } \\
\text { (actual or } \\
\text { simulated) }\end{array}$ & $\begin{array}{l}\text { Participates } \\
\text { in disclosure } \\
\text { of patient } \\
\text { safety events } \\
\text { to patients } \\
\text { and families } \\
\text { (simulated or } \\
\text { actual) }\end{array}$ & $\begin{array}{l}\text { Discloses } \\
\text { patient } \\
\text { safety } \\
\text { events to } \\
\text { patients and } \\
\text { families } \\
\text { (simulated } \\
\text { or actual) }\end{array}$ & $\begin{array}{l}\text { Role models } \\
\text { or mentors } \\
\text { others in the } \\
\text { disclosure of } \\
\text { patient safety } \\
\text { events }\end{array}$ \\
\hline $\begin{array}{l}\text { Demon- } \\
\text { strates } \\
\text { knowledge } \\
\text { of basic } \\
\text { quality } \\
\text { improve- } \\
\text { ment } \\
\text { methodolo- } \\
\text { gies and } \\
\text { metrics }\end{array}$ & $\begin{array}{l}\text { Describes } \\
\text { local quality } \\
\text { improve- } \\
\text { ment } \\
\text { initiatives } \\
\text { (e.g., } \\
\text { community } \\
\text { vaccination } \\
\text { rate, infec- } \\
\text { tion rate, } \\
\text { smoking } \\
\text { cessation) }\end{array}$ & $\begin{array}{l}\text { Participates } \\
\text { in local } \\
\text { quality } \\
\text { improvement } \\
\text { initiatives }\end{array}$ & $\begin{array}{l}\text { Demon- } \\
\text { strates the } \\
\text { skills } \\
\text { required to } \\
\text { identify, } \\
\text { develop, } \\
\text { implement, } \\
\text { and analyze } \\
\text { a quality } \\
\text { improve- } \\
\text { ment project }\end{array}$ & $\begin{array}{l}\text { Creates, } \\
\text { implements, } \\
\text { and assesses } \\
\text { quality } \\
\text { improvement } \\
\text { initiatives at } \\
\text { the } \\
\text { institutional } \\
\text { or community } \\
\text { level }\end{array}$ \\
\hline
\end{tabular}

Ref. [40]

Reprinted by permission of the ACGME. All rights reserved.

"Simply stated, the Milestones describe performance levels residents and fellows are expected to demonstrate for skills, knowledge, and behaviors in the six clinical competency domains. They lay out a 
framework of observable behaviors and other attributes associated with a resident's or fellow's development as a physician. The Milestones' primary purpose is to drive improvement in training programs and enhance the resident and fellow educational experience." [39]

Milestones were officially launched in 2013 in seven core specialties (emergency medicine, internal medicine, neurological surgery, orthopedic surgery, pediatrics, diagnostic radiology, and urology) as a component of the new accreditation system. The remaining core disciplines and the majority of subspecialties implemented the milestones a year later.

The CLER program and the Milestones have transformed residency training from an apprentice system-“do what I do"-measured by time served, into an educational system measured by competency achieved through planned experiences that include not only technical competency and knowledge, but experience in quality and safety and systems improvement.

\section{Duty Hours}

What happened about duty hours? Opposition to the 80-hour limit died a quiet death as evidence piled up against it. The ACGME funded two randomized trials that compared programs that strictly adhered to the rules to those with the flexible ones. The results showed that violations of 80 -hour rules were linked to increased depression, suicide, and harm, such as needlestick injuries [25]. They also showed no differences in outcomes among surgery programs, leading to the conclusion that they should be bound by the same hour limits [41].

The other bit of evidence that the 80-hour limit was not harmful came from New York. The state had been strictly enforcing the 80-hour limit, with substantial fines, for a long time. No one could prove that physicians trained in New York were less competent. Skeptics began to come around. At the 2015 ACGME conference of Review Committees and others interested in graduate medical education, every medical organization agreed on the 80-hour limit. Shortly 
afterward it was adopted as a standard. The ACGME now cites programs if more than one resident in a program has violated the 80-hour limit.

Is the issue of duty hours settled, then? Hardly. Why is an 80-hour work week acceptable? Why is 13 hours a day, 6 days a week, with 1 weekend off a month considered humane given the damage it does to residents' well-being and family life? Talk about "normalizing deviance"!

Why do we turn a blind eye to the experience of the rest of the Western world - the EU limits that show competent and caring doctors can be trained in 48 hours a week? Forty-eight versus eighty! A world of difference. Could we train good-excellent-doctors in 48 hours a week, or at most 60 ? Of course we could.

They might even be better doctors. One of the major lessons in patient safety is that you can't expect health-care workers to care about patients' safety when you don't care about worker safety. Why do we think that treating doctors inhumanely will lead them to be kind and caring for their patients? Perhaps patients' complaints about how they are treated by their physician stem from how we treat the doctors during their formative training years.

\section{Conclusion}

What do we make of all this? The conflict over duty hours subsided with the "victory" of the 80-hour work week. On the other hand, the aggressive stance of the ACGME regarding the learning environment has been a welcome change and the CLER program has had an impact.

The implications for patient safety are also profound. A major stumbling block in advancing patient safety has been the lack of buyin by most physicians; they don't "own” it. As Kevin Weiss points out, the profession doesn't "own" anything until it makes it an expectation of training and builds it into the training standards for the profession. That is where we agree on the definition of what the next generation must know and be able to do. Where we agree on who we are. The 
requirements for accreditation are therefore essential to how the profession is able to establish professional identity for all those who enter the profession (Kevin B. Weiss, MD, personal communication, May 20, 2020).

The groundwork was laid when the ABMS and ACGME agreed on the six domains of competency that included systems-based practice. The turning point was when ACGME expectations for training programs based on the six competencies became requirements. After evidence showed that programs were falling woefully short, the first CLER report outlined the needs for learning in quality and safety. These were later cut and pasted as requirements for accreditation.

Thanks to Tom Nasca and the ACGME, residency training has changed more in the past 20 years than in all of the previous 100. It is finally beginning to become more about education than service, about creating good physicians, not exploiting them. We now aspire to educate the whole physician, one who is skilled and expert, works well with others in teams, and communicates well with patients and colleagues.

The duty hours issue still needs work. We still have sleepy doctors. It's time to say good-bye to the 80-hour week and create a more humane environment. But we've made immense progress, and we are almost certainly turning out better doctors.

\section{References}

1. Lerner BH. A case that shook medicine: how one man's rage over his daughter's death sped reform of doctor training. The Washington Post. 2006; Lifestyle.

2. Sack K. Appeals court clears doctors who were censured in the Libby Zion case. The New York Times. 1991;B:2.

3. 2001 AAMC survey of housestaff stipends, senefits and funding. Washington, DC: AAMC; 2001.

4. New York State Department of Health's Ad Hoc Advisory Committee on Emergency Services. Supervision and residents' working conditions. New York; 1987. 
5. New York Codes, Rules, and Regulations, Title 10 Section 405.4 Medical Staff (10 CRR-NY 405.4). In: New York State Department of Health, ed; 1988.

6. Lees DE. New York state regulations to be implemented. Anesth Patient Saf Found Newsl. 1988;3(3)

7. Accreditation. Accreditation Council for Graduate Medical Education (ACGME). https://www.acgme.org/What-We-Do/Accreditation. Accessed 6 June 2020.

8. Resident assessment: compliance with working hour and supervision requirements. New York: New York State Department of Health; 1998.

9. Health Care Reform Act of 2000, Bill No. A09093/S06187. In: New York State Assembly.

10.Gurjala A, Lurie P, Wolfe S. Petition to the occupational safety and health administration requesting that limits be placed on hours worked by medical residents (HRG Publication \#1570). Public Citizen. https://www.citizen.org/ article/petition-requesting-medical-residents-work-hour-limits/. Published April 30, 2001. Accessed 6 June 2020.

11.H.R.3236 - Patient and Physician Safety and Protection Act of 2001. In: House of Representatives 107th Congress 1st Session, ed: U.S. Congress.

12. Barnard A. Surgery residents' long hours draw warning for Yale. The Boston Globe. 2002;A1.

13.Philibert I, Friedmann P, Williams WT. Education AWGoRDHACfGM. New requirements for resident duty hours. JAMA. 2002;288(9):1112-4.

14.Daugherty SR, Baldwin JDC, Rowley BD. Learning, satisfaction, and mistreatment during medical internship: a national survey of working conditions. JAMA. 1998;279(15):1194-9.

15.Schwartz RJ, Dubrow TJ, Rosso RF, Williams RA, Butler JA, Wilson SE. Guidelines for surgical residents' working hours: intent vs reality. Arch Surg. 1992;127(7):778-83.

16.Report of the ACGME Work Group on Resident Duty Hours. Chicago: Accreditation Council for Graduate Medical Education; 2002.

17.Sleep-Deprived Doctors. The New York Times. June 14, 2002; Editorials/ Letters: A36.

18.Gabehart RJ, Van Dongen HPA. Circadian rhythms in sleepiness, alertness, and performance. In: Kryger MH, Roth T, Dement WC, editors. Principles and practice of sleep medicine. 6th ed. Philadelphia: Elsevier; 2011. p. 388-95.

19.Dinges DF, Pack F, Williams K, et al. Cumulative sleepiness, mood disturbance, and psychomotor vigilance performance decrements during a week of sleep restricted to 4-5 hours per night. Sleep. 1997;20(4):267-77.

20.Dawson D, Reid K. Fatigue, alcohol and performance impairment. Nature. 1997;388(6639):235. 
21.Gaba DM, Howard SK. Fatigue among clinicians and the safety of patients. N Engl J Med. 2002;347(16):1249-55.

22.Landrigan C, Rothschild J, Cronin J, et al. Effect of reducing interns' work hours on serious medical errors in intensie care units. N Engl J Med. 2004;351:1838-48.

23. Czeisler CA. Medical and genetic differences in the adverse impact of sleep loss on performance: ethical considerations for the medical profession. Trans Am Clin Climatol Assoc. 2009;120:249-85.

24. Weinger MB, Ancoli-Israel S. Sleep deprivation and clinical performance. JAMA. 2002;287(8):955-7.

25. Ayas NTB, Barger LK, Cade BE, Hashimoto DM, Rosner B, Cronin JW, Speizer FE, Czeisler CA. Extended work duration and the risk of selfreported percutaneous injuries in interns. JAMA. 2006;296(9):1055-62.

26. Barger L, Cade BE, Ayas NT, et al. Extended work shifts and the risk of motor vehicle crashes among interns. N Engl J Med. 2005;352:125-34.

27.Drazen JM, Epstein AM. Rethinking medical training--the critical work ahead. N Engl J Med. 2002;347(16):1271-2.

28. Stoddard JJ, Kindig DA, Libby D. Graduate medical education reform: service provision transition costs. JAMA. 1994;272(1):53-8.

29.Landrigan CPB, Barger LK, Cade BE, Ayas NT, Czeisler CA. Interns' compliance with accreditation council for graduate medical education work-hour limits. JAMA. 2006;296(9):1063-70.

30.Lockley S, Cronin JW, Evans EE, et al. Effect of reducing interns' weekly work hours on sleep and attentional failures. N Engl J Med. 2004;351:1829-37.

31.Levine AC, Adusumilli J, Landrigan CP. Effects of reducing or eliminating resident work shifts over 16 hours: a systematic review. Sleep. 2010;33(8):1043-53.

32.Reed DA, Fletcher KE, Arora VM. Systematic review: association of shift length, protected sleep time, and night float with patient care, residents' health, and education. Ann Intern Med. 2010;153(12):829-42.

33.Ulmer C, Wolman D, Johns M. Resident duty hours. Washington: The National Academies Press; 2009.

34.Nasca TJ, Day SH, Amis ES. The new recommendations on duty hours from the ACGME task force. N Engl J Med. 2010;363(2):e3.

35.Blum AB, Shea S, Czeisler C, Landrigan CP, Leape L. Implementing the 2009 Institute of Medicine recommendations on resident physician work hours, supervision, and safety. Nature Sci Sleep. 2011;3:47-85.

36. Blum AB, Raiszadeh F, Shea S, et al. US public opinion regarding proposed limits on resident physician work hours. BMC Med. 2010;8(33). Published online 2010 Jun 1. https://doi.org/10.1186/1741-7015-8-33.

37.Nasca TJ, Philibert I, Brigham T, Flynn TC. The next GME accreditation system — rationale and benefits. N Engl J Med. 2012;366(11):1051-6.

38. Clinical Learning Environment Review (CLER). Accreditation Council for Graduate Medical Education (ACGME). https://www.acgme.org/ 
What-We-Do/Initiatives/Clinical-Learning-Environment-ReviewCLER. Accessed 6 June 2020.

39. Holmboe ES, Edgar L, Hamstra S. The milestones guidebook: ACGME; 2016.

40. Holmboe ES, Yamazaki K, Edgar L, et al. Reflections on the first 2 years of milestone implementation. J Grad Med Educ. 2015;7(3):506-11.

41.Rosen KA, Loveland AS, Romano SP, et al. Effects of resident duty hour reform on surgical and procedural patient safety indicators among hospitalized veterans health administration and medicare patients. Med Care. 2009;47(7):723-31.

Open Access This chapter is licensed under the terms of the Creative Commons Attribution 4.0 International License (http://creativecommons.org/ licenses/by/4.0/), which permits use, sharing, adaptation, distribution and reproduction in any medium or format, as long as you give appropriate credit to the original author(s) and the source, provide a link to the Creative Commons license and indicate if changes were made.

The images or other third party material in this chapter are included in the chapter's Creative Commons license, unless indicated otherwise in a credit line to the material. If material is not included in the chapter's Creative Commons license and your intended use is not permitted by statutory regulation or exceeds the permitted use, you will need to obtain permission directly from the copyright holder.

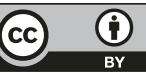

